\title{
An application of mathematical programming and sequential Gaussian simulation for block cave production scheduling
}

\author{
S Malaki University of Alberta, Canada \\ F Khodayari University of Alberta, Canada \\ Y Pourrahimian University of Alberta, Canada \\ WV Liu University of Alberta, Canada
}

\begin{abstract}
The current trend of deeper and lower-grade deposits makes open pit mining less profitable. Mass mining alternatives have to be developed if mining at a similar rate is to be continued. Block cave mining is becoming an increasingly popular mass mining method, especially for large copper deposits currently being mined with open pit methods.

After finding the initial evaluation of a range of levels for starting the extraction of block cave mining, production scheduling plays a key role in the entire project's profitability. Traditional long-term mine planning is based on deterministic orebody models, which can ignore the uncertainty in the geological resources.

The purpose of this paper is to present a methodology to find the optimal extraction horizon and sequence of extraction for that horizon under grade uncertainty. The model does not explicitly take into account other potential project value drivers such as waste ingress into the draw column or the impact of primary or secondary fragmentation on either production or recovery. Maximum net present value (NPV) is determined using a mixed-integer linear programming (MILP) model after choosing the optimum horizon of extraction given some constraints such as mining capacity, production grade, extraction rate and precedence. Application of the method for block cave production scheduling using a case study over 15 periods is presented.
\end{abstract}

Keywords: block caving, grade uncertainty, sequential Gaussian simulation, production scheduling

\section{Introduction}

Among the underground mining methods available, caving methods are favoured because of their low operational costs and high production rates. Production scheduling in block caving, because of its significant impact on the project's value, has been considered a key issue to be improved. To that end, researchers have applied different methods, such as mathematical programming, to model production scheduling in block caving (Chanda 1990; Diering 2004, 2012; Epstein et al. 2012; Guest et al. 2000; Khodayari \& Pourrahimian 2014, 2015a, 2016; Parkinson 2012; Pourrahimian 2013; Pourrahimian \& Askari-Nasab 2014; Pourrahimian et al. 2013; Rahal et al. 2008; Rubio 2002; Rubio \& Diering 2004; Smoljanovic et al. 2011; Song 1989; Weintraub et al. 2008).

These models are built to help the decision-maker evaluate the consequences of various management alternatives. In order to be most useful, the decision support model should also include information about the uncertainties related to each of the decision options, as the certainty of the desired outcome may be the central criterion for the selection of the management policy.

Ore grade is one of the crucial parameters subject to uncertainty in mining operations. Grade uncertainty can lead to significant differences between actual production outcomes and planning expectations and, as a result, the net present value (NPV) and internal rate of return (IRR) of the project (Koushavand \& Askari-Nasab 2009; Osanloo et al. 2008). Various researchers have considered the effects of grade uncertainty in open pit mines and have introduced different methodologies to address those effects (Albor Consuegra \& 
Dimitrakopoulos 2009; Asad \& Dimitrakopoulos 2013; Dimitrakopoulos \& Ramazan 2008; Dowd 1994; Koushavand \& Askari-Nasab 2009; Lamghari \& Dimitrakopoulos 2012; Lamghari et al. 2013; Leite \& Dimitrakopoulos 2007; Maleki \& Emery 2015; Ramazan \& Dimitrakopoulos 2004, 2013; Ravenscroft 1992; Sabour \& Dimitrakopoulos 2011).

Other than the aforementioned authors, few authors have examined geological uncertainty in underground mining. Grieco and Dimitrakopoulos (2007) implemented a new probabilistic mixed-integer programming model which optimises the stope designs in sublevel caving. Vargas et al. (2014) developed a tool that considered geological uncertainty by using a set of conditional simulations of the mineral grades and defining the economic envelope in a massive underground mine. Montiel et al. (2015) incorporated geological uncertainty into their methodology that optimises mining operation factors such as blending, processing and transportation. They used a simulated annealing algorithm to deal with uncertainty. Carpentier et al. (2016) introduced an optimisation formulation that looked at a group of underground mines under geological uncertainty. Their formulation evaluates the project's influence on economic parameters including capital investments and operational costs.

One of the main steps involved in optimising underground mines is determining a cutoff grade and its associated mining outline and contained mineral inventory. The open pit corollary to this is open pit optimisation, which is completed with algorithms such as those by Lerchs and Grossmann (1965).

To optimise block caving scheduling, most researchers have used mathematical programming: linear programming (LP), mixed-integer linear programming (MILP), quadratic programming (QP), mixed-integer quadratic programming (MIQP), and mixed-integer linear goal programming (MILGP) (Chanda 1990; Diering 2004, 2012; Epstein et al. 2012; Guest et al. 2000; Khodayari \& Pourrahimian 2014, 2015a, 2016; Parkinson 2012; Pourrahimian 2013; Pourrahimian \& Askari-Nasab 2014; Pourrahimian et al. 2013; Rahal et al. 2008; Rubio 2002; Rubio \& Diering 2004; Smoljanovic et al. 2011; Song 1989; Weintraub et al. 2008). Khodayari and Pourrahimian (2015b) presented a comprehensive review of operations research in block caving.

This paper will introduce a method designed to identify the optimal horizon for initialising extraction according to the maximum discounted ore profit under grade uncertainty. The model does not explicitly take into account other potential project values drivers such as waste ingress into the draw column or the impact of primary or secondary fragmentation on either production or recovery. Several realisations are modelled by using geostatistical studies to consider grade uncertainty. The production schedule is generated for the given advancement direction and in the presence of constraints such as mining capacity, grade of production, reserve, precedence, and number of active blocks at the chosen level.

\section{$2 \quad$ Methodology}

The orebody is represented by a geological block model. Numerical data are used to represent each block's attributes, such as tonnage, density, grade, rock type, elevation, and economic value.

The first step is to construct a block model based on the drillhole data and the grid definition. The next step is a geostatistical study to generate the realisations. Then, the optimal extraction horizon is identified for each realisation. Finally, the optimal sequence of extraction is determined to maximise the NPV.

\subsection{Geological uncertainty}

The first step for a geostatistical study is to define different rock types based on the drillhole data. In this study, which assumes a stationary domain within each rock type, the geostatistical modelling is performed for each rock type separately. The following steps are common for generating a geological model: First, a declustering algorithm is used to get the representative distribution of each rock type to decrease the weight of clustered samples. Then, the correlation of the multivariate data is determined. To determine the principal directions of continuity, global kriging is performed using arbitrary variograms with a high range. Indicator kriging is used for rock type modelling, and simple kriging is used for grade modelling. The data is transformed to Gaussian units to remove the correlation between the variables in each rock type. 
The experimental variograms are calculated by using the determined directions of continuity in the previous step, and a model is fitted to these variograms in different directions. An indicator variogram is used for rock type modelling, and a traditional variogram is used for grade modelling. A rock type model is generated for the chosen grid definition by using a sequential indicator simulation algorithm (SIS). A grade model for each rock type is generated based on a sequential Gaussian simulation algorithm (SGS). Then, the data is back-transformed to original units. Finally, grade modelling is done within each rock type.

\subsection{Placement of extraction level}

To find the optimum horizon of extraction, the ore tonnage and discounted profit are calculated for each level of the block model. The discounted profit of each ore block (Diering et al. 2008) and the total discounted profit of each level are calculated using Equations 1 and 2. Then, the tonnage-profit curve is plotted, and the level with the highest profit is selected for starting the extraction.

$$
\begin{aligned}
& \text { Dis } \mathrm{P}_{b l L}=\frac{\operatorname{Pr}}{(1+i)^{d / E R}} \\
& \text { Dis } \mathrm{P}_{L}=\sum_{b l=1}^{B L} \text { Dis } \mathrm{P}_{b l L}
\end{aligned}
$$

where:
Dis $P_{b / L}=$ the discounted profit of ore block $b /$ in level $L$ and the above blocks.
Dis $P_{L} \quad=$ the total discounted profit of level $L$.
$\operatorname{Pr} \quad=$ the profit of ore block $b l$ and ore blocks above it.

i $\quad=$ the discount rate.

d $\quad=$ the distance between the centre points of ore block $b /$ in level $L$ and the ore blocks above it.
$E R \quad=\quad$ the extraction rate per period.
$B L=$ the total number of ore blocks in level $L$.

After determining the optimal elevation, the interior of the orebody outline is divided into rectangles based on the required minimum mining footprint. The minimum mining footprint represents the minimum-sized shape that will induce and sustain caving in the overlying rock. This is equivalent to the hydraulic radius in a caving operation. Then, all blocks inside of the rectangle and above that create big-blocks. In the next step, the sequence of extraction of these big-blocks is optimised using an MILP model (Figure 1).

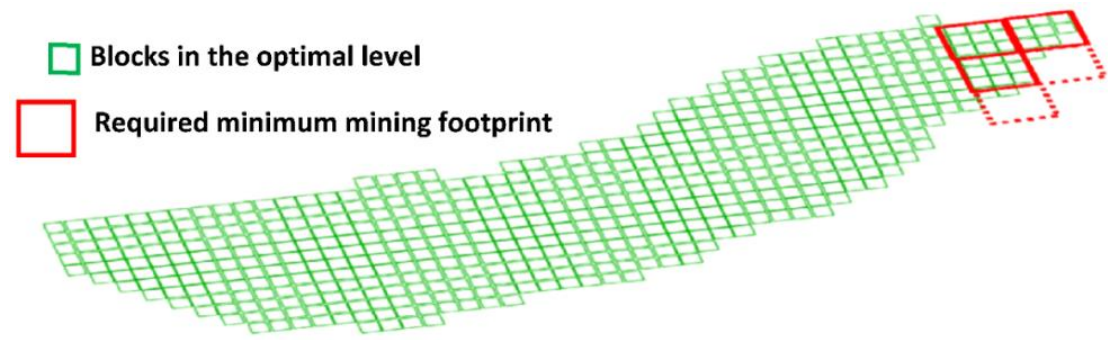

Figure 1 Dividing the interior of orebody into rectangles based on the required minimum mining footprint

The MILP model is developed in MATLAB (The MathWorks, Inc. 2017), and solved in the IBM ILOG CPLEX environment (IBM 2015). A branch-and-bound algorithm is used to solve the MILP model, assuring an optimal solution if the algorithm is run to completion. A gap tolerance (EPGAP) is used as an optimisation termination criterion. This is an absolute tolerance between the gap of the best integer objective and the objective of the remained best node. 


\section{Mathematical formulation}

The notation of sets, indices and decision variables for the MILP model are as follows (Table 1):

Table 1 Decision variables, set, indices, and parameters of the MILP model

\begin{tabular}{|c|c|}
\hline \multicolumn{2}{|l|}{ Indices } \\
\hline$t \in\{1, \ldots ., T\}$ & Index for scheduling periods. \\
\hline$b l \in\{1, \ldots, B L\}$ & Index for small-blocks. \\
\hline$b b l \in\{1, \ldots, B B L\}$ & Index for big-blocks. \\
\hline \multicolumn{2}{|l|}{ Set } \\
\hline$S^{b b l}$ & $\begin{array}{l}\text { For each big-block, } b b l \text {, there is a set } S^{b b l} \text {, which defines the predecessor big-blocks } \\
\text { that must be started prior to extracting the big-block } b b l \text {. }\end{array}$ \\
\hline \multicolumn{2}{|c|}{ Decision variables } \\
\hline$B_{b b l, t} \in\{0,1\}$ & $\begin{array}{l}\text { Binary variable controlling the precedence of the extraction of big-blocks. It is equal to } \\
\text { one if the extraction of big-block, } b b l \text {, has started by or in period } t \text {; otherwise, it is zero. }\end{array}$ \\
\hline $\mathrm{x}_{b b l, t} \in[0,1]$ & $\begin{array}{l}\text { Continuous variable, representing the portion of big-block } b b / \text { to be extracted in } \\
\text { period } t \text {. }\end{array}$ \\
\hline$y_{b b l, t} \in\{0,1\}$ & Binary variable used for activating either of two constraints. \\
\hline \multicolumn{2}{|l|}{ Parameters } \\
\hline Profit $t_{b b l}$ & Profit of big-block bbl. \\
\hline $\operatorname{Ton}_{b b l}$ & Tonnage of big-block bbl. \\
\hline$M C L(M t)$ & Lower bound of mining capacity. \\
\hline$M C U(M t)$ & Upper bound of mining capacity. \\
\hline$g_{b b l}$ & Average grade of the element to be studied in big-block $b b l$. \\
\hline$G L(\%)$ & Lower bound of the acceptable average head grade of considered element. \\
\hline$G U(\%)$ & Upper bound of the acceptable average head grade of considered element. \\
\hline $\operatorname{Ext} U(M t)$ & Maximum possible extraction rate from each big-block. \\
\hline $\operatorname{Ext} L(M t)$ & Minimum possible extraction rate from each big-block. \\
\hline$L$ & Arbitrary big number. \\
\hline$T$ & Maximum number of scheduling periods. \\
\hline$B B L$ & Number of ore big-blocks in the model. \\
\hline$n$ & Number of predecessor big-blocks of big-block $b b l$. \\
\hline $\bar{N}_{N B B L, t}$ & $\begin{array}{l}\text { Upper bound for the number of new big-blocks, the extraction from which can start } \\
\text { in period } t \text {. }\end{array}$ \\
\hline$\underline{N}_{N B B L, t}$ & $\begin{array}{l}\text { Lower bound for the number of new big-blocks, the extraction from which can start } \\
\text { in period } t \text {. }\end{array}$ \\
\hline
\end{tabular}




\subsection{Objective function and constraints}

\subsubsection{Objective function}

The objective function of the MILP formulation is to maximise the NPV of the mining operation, which depends on the value of the big-blocks. The objective function, Equation 3, is composed of the big-blocks' profit value, discount rate, and a continuous decision variable that indicates the portion of a big-block, which is extracted in each period. The most profitable big-blocks will be chosen to be part of the production in order to maximise the NPV.

$$
\operatorname{Max} \sum_{t=1}^{T} \sum_{b b l=1}^{B B L} \frac{\operatorname{Pr} o f i t_{b b l} \times x_{b b l, t}}{(1+i)^{t}}
$$

\subsubsection{Constraints}

\subsubsection{Mining capacity}

These constraints ensure that the total tonnage of material extracted from each big-block in each period is within the acceptable range. The constraints are controlled by the continuous variables.

$$
M C L_{t} \leq \sum_{b b l=1}^{B B L} \operatorname{Ton}_{b b l} \times x_{b b l, t} \leq M C U_{t}
$$

\subsubsection{Grade of production}

These constraints ensure that the production's average grade is in the acceptable range.

$$
G L_{t} \leq \frac{\sum_{b b l=1}^{B B L} g_{b b l} \times T_{b b l} \times x_{b b l, t}}{\sum_{b b l=1}^{B B L} T o n_{b b l} \times x_{b b l, t}} \leq G U_{t}
$$

\subsubsection{Block extraction rate and continuous extraction}

Equation 6 ensures that the extraction rate from each big-block per period does not exceed the maximum extraction rate. $y_{b b l, t}$ in Equations 7 and 8 is a binary variable that is used to activate either Equation 7 or 8. Whenever Equation 7 is active, it ensures that the minimum extraction rate from each big-block per period is activated. If the remaining tonnage of a big-block is less than the minimum extraction rate, Equation 8 will be activated and forces that big-block to be extracted as much as the remaining tonnage which results in continuous extraction from each big-block.

$$
\begin{gathered}
\operatorname{Ton}_{b b l} \times x_{b b l, t} \leq E x t U_{b b l, t} \\
\left(E x t L_{b b l, t} \times B_{b b l, t}\right)-\left(\operatorname{Ton}_{b b l} \times x_{b b l, t}\right) \leq L \times y_{b b l, t} \\
\sum_{t=1}^{t} x_{b b l, t} \geq y_{b b l, t}
\end{gathered}
$$




\subsubsection{Binary constraints}

Equation 9 ensures that if the extraction of one big-block is started, its binary variable should be one. Also, Equation 10 controls the fact that if the extraction of one big-block in period $t$ has been started $\left(B_{b b l, t}=1\right)$, the related binary variable should be kept as one until the end of the mine life. Both Equations 8 and 10 contribute to the continuity of the extraction. The results of these constraints will be used for the precedence constraint for which the maximum number of active big-blocks is needed.

$$
\begin{gathered}
\mathrm{x}_{b b l, t} \leq B_{b b l, t} \\
B_{b b l, t}-B_{b b l, t+1} \leq 0
\end{gathered}
$$

\subsubsection{Number of new big-blocks}

Equations 11 and 12 ensure that the number of new big-blocks in each period are in an acceptable range. It is obvious that the number of new drawpoints in period one is more than other periods, therefore, Equation 11 is applied to period one and Equation 12 is applied from period two to the end of the mine's life.

$$
\begin{gathered}
\underline{N}_{N B B L, 1} \leq \sum_{b b l=1}^{B B L} B_{b b l, t} \leq \bar{N}_{N B B L, 1} \\
\underline{N}_{N B B L, t} \leq \sum_{b b l=1}^{B B L} B_{b b l, t}-\sum_{b b l=1}^{B B L} B_{b b l, t-1} \leq \bar{N}_{N B B L, t}
\end{gathered}
$$

\subsubsection{Precedence}

Equation 13 ensures that all the predecessor big-blocks of a given big-block $b b /$ have been started prior to extracting this big-block.

$$
n \times B_{b b l, t} \leq \sum_{k=0}^{n} B_{S^{b b l}(k), t}
$$

\subsubsection{Reserve}

In this formulation, all material inside of the big-blocks should be extracted. This is controlled by Equation 14.

$$
\sum_{t=1}^{T} x_{b b l, t}=1
$$

\section{$4 \quad$ Case study}

\subsection{Grade uncertainty}

A geostatistical study based on the drillhole data of a copper deposit was performed and a block model constructed. Geostatistical software library (GSLIB) (Deutsch \& Journel 1998) was used for geostatistical modelling in this paper. The initial inspection of the locations of the drillholes showed that the drillholes were equally spaced. As a result, the declustering algorithm was not implemented. There were two parts to the modelling: rock type modelling and grade modelling. The grade modelling was implemented for both rock types (ore and waste) separately. 


\subsubsection{Rock type modelling}

The principal directions of continuity were found using indicator kriging. Afterwards, the indicator variograms were calculated and a theoretical variogram model was fitted with three structures. In Figure 2, the top left image shows the plan view of the maximum direction of continuity for rock types at Elevation 40 and experimental directional variograms (dots) and the fitted variogram models (solid lines) for rock type and distance units in metres. In the next step, 20 realisations for rock types were generated using an SIS algorithm. A plan view of the rock type simulation for the first realisation at Elevation 40 is shown in Figure 2 (top right).

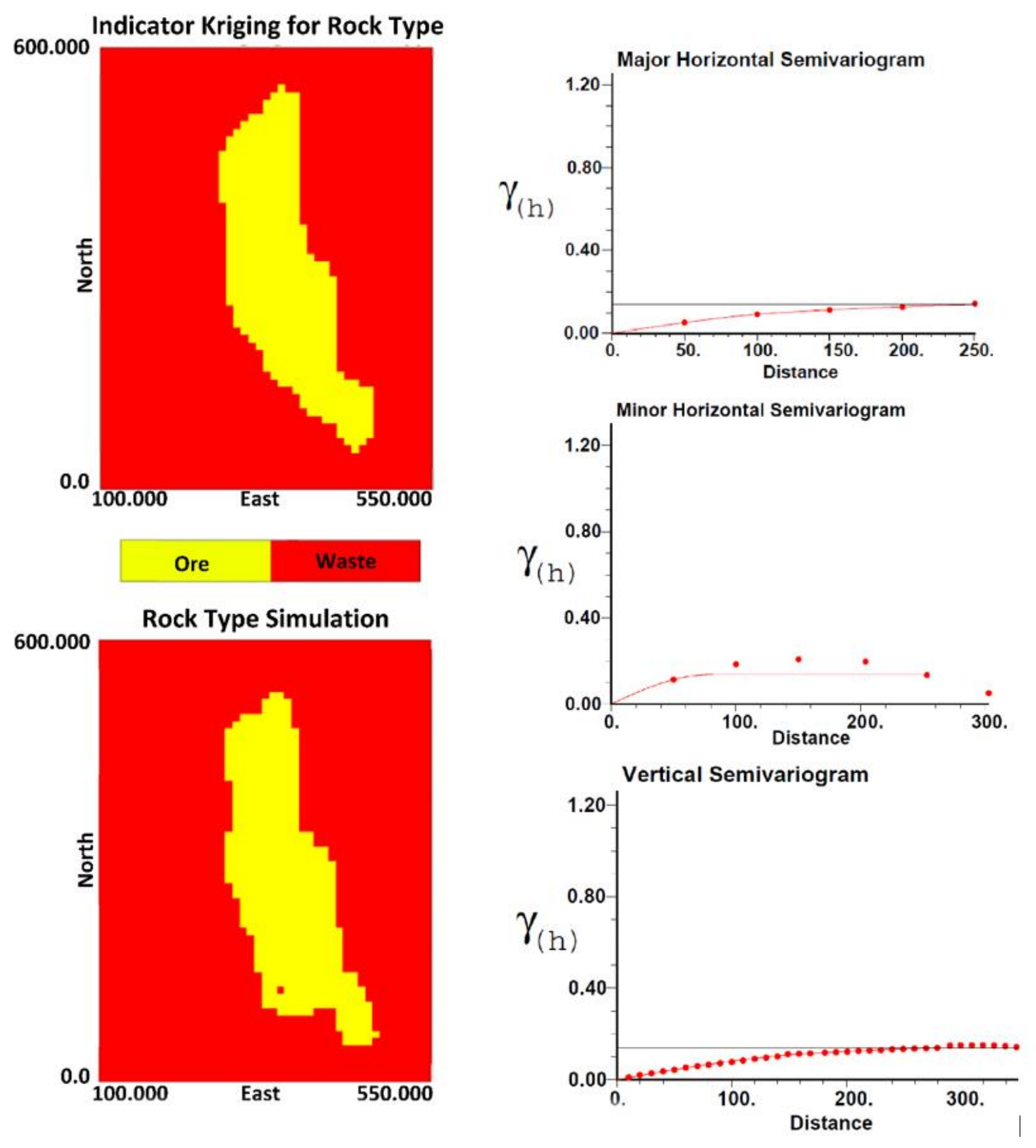

Figure 2 Dividing rock type modelling and simulation 


\subsubsection{Grade modelling}

For ore modelling, the principal directions of continuity were extracted by doing simple kriging with the help of arbitrary variograms. Then, the copper grades were transformed to Gaussian space. In Figure 3, the top left image shows a plan view of the maximum direction of continuity for the copper grade at Elevation 40. Traditional variogram calculation and modelling with three structures and a nugget effect of 0.1 was performed for the copper grade. Afterwards, 20 realisations for the copper grade were generated using SGS algorithms. The SGS needs a back-transformation to original units. The plan view of copper grade simulation for the first realisation at Elevation 40 is shown in Figure 3 (top right).

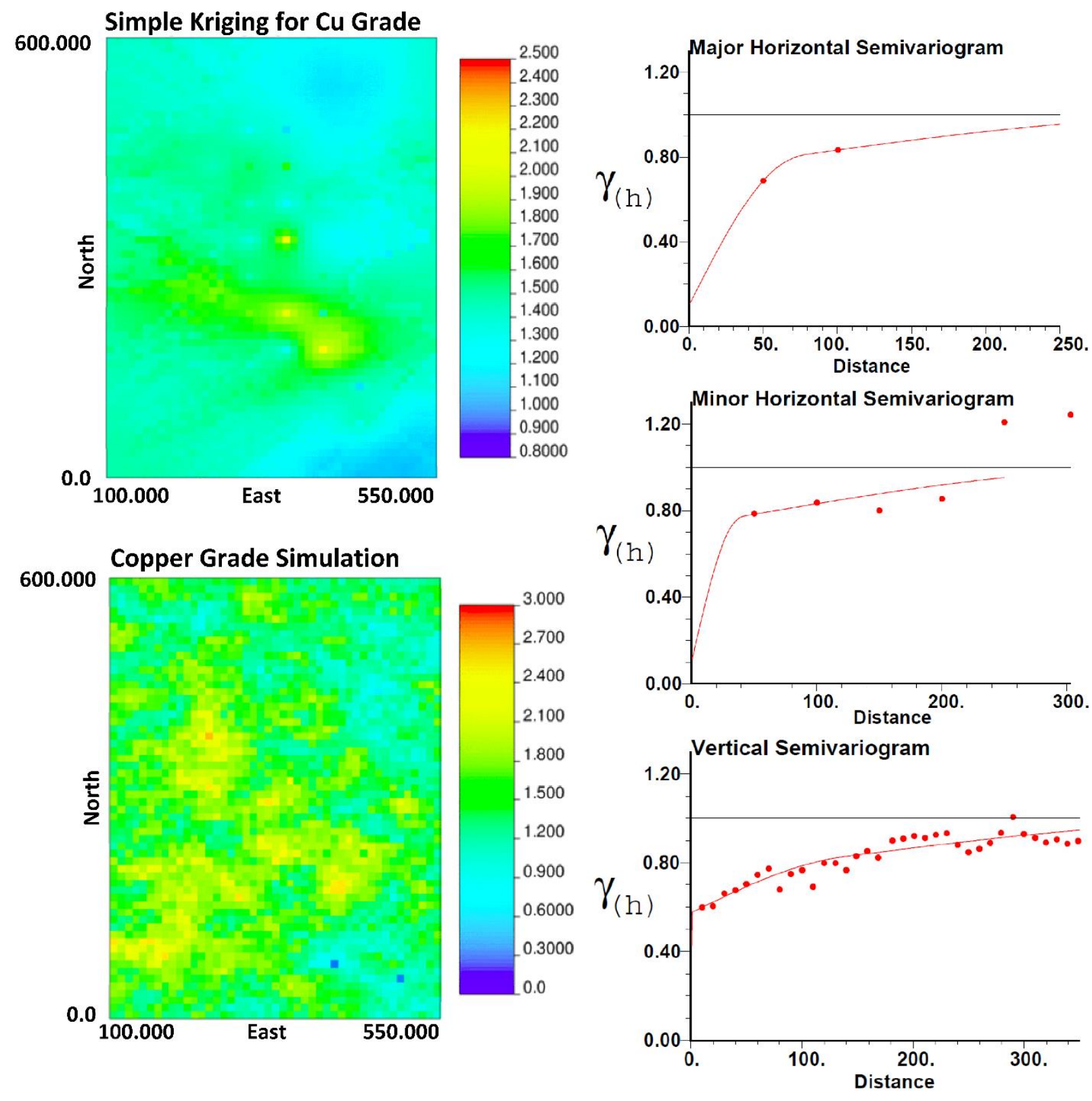

Figure 3 Grade modelling and simulation 
The next step was to match and merge the rock type model with the grade model for each realisation. Figure 4 shows the plan view of the final simulation for the first realisation. Figure 5 shows the variogram reproduction of the rock property (ore) simulation (top) and rock type simulation (bottom) in three major, minor, and vertical directions. Since the variograms were reproduced quite reasonably, the generated realisations were considered representative of the grade uncertainty.

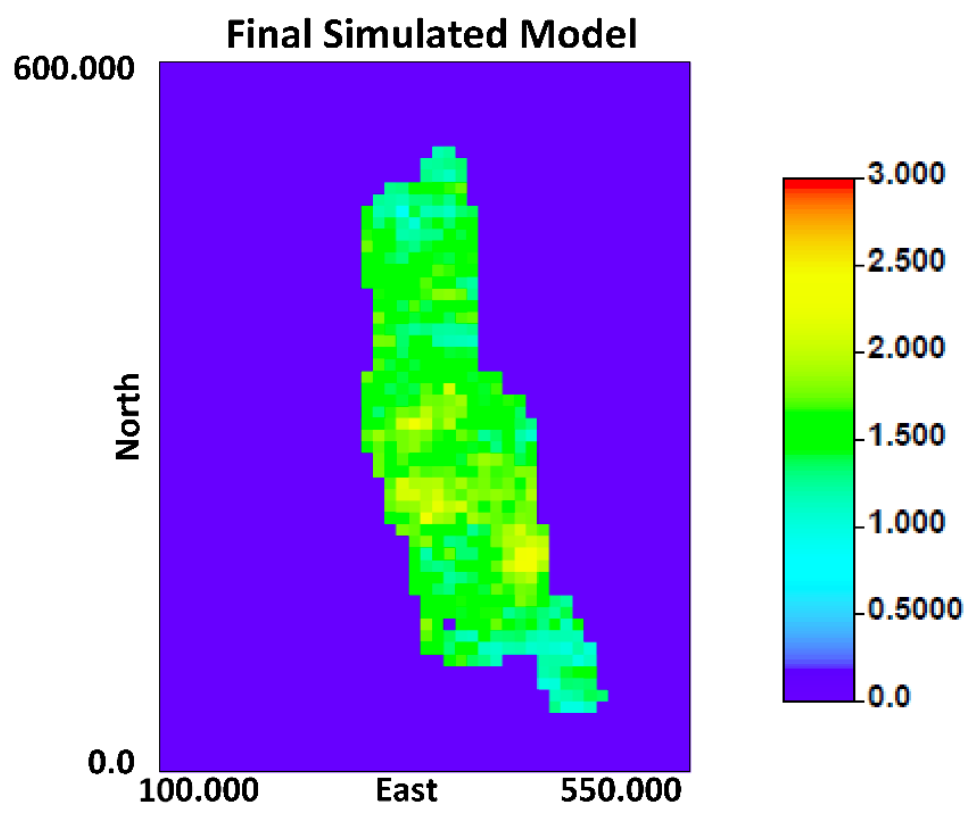

Figure 4 Final simulation of the first realisation at Elevation 40
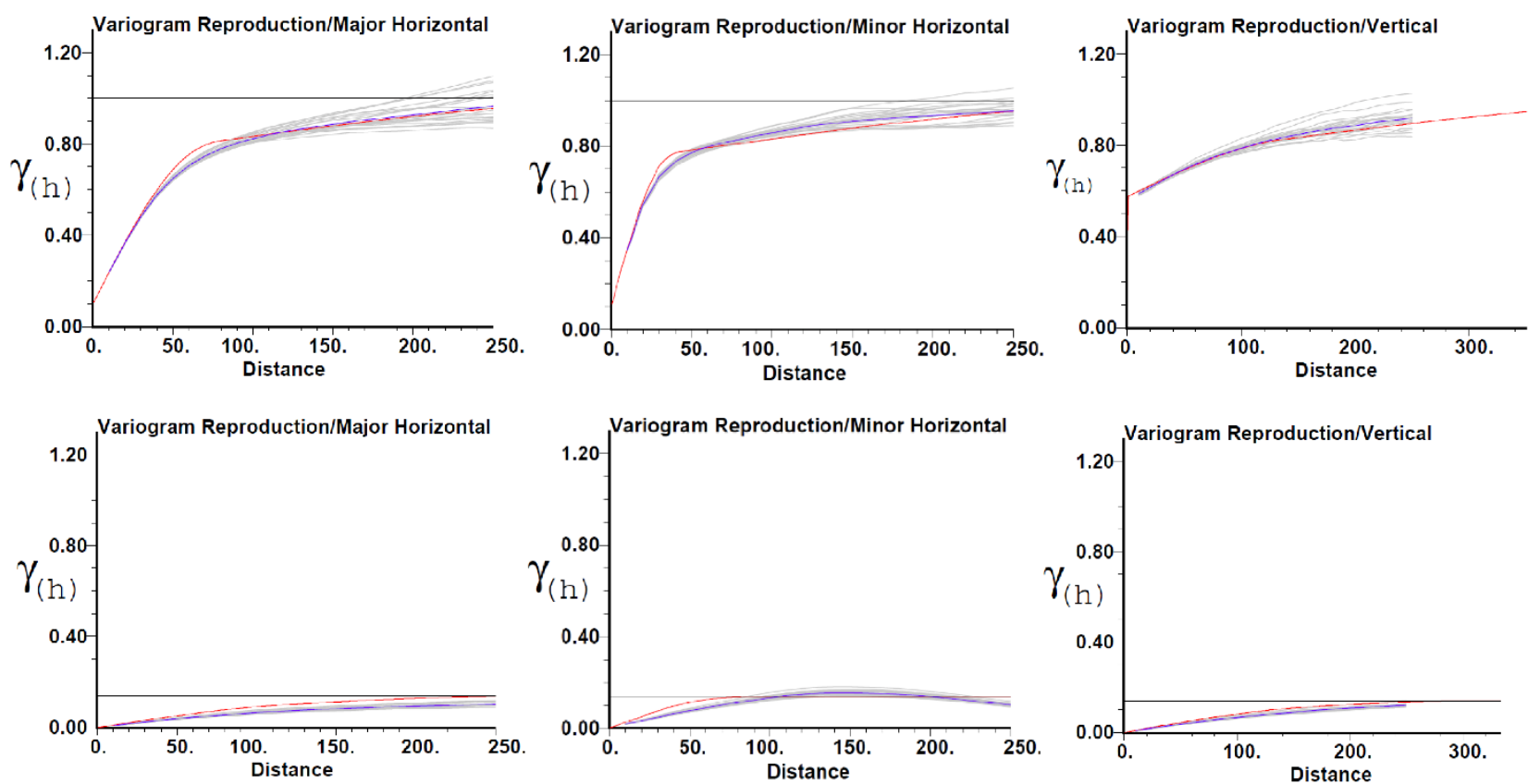

Figure 5 Variogram reproduction at Gaussian units of copper grade (top) and rock type (bottom) realisations (grey lines), the reference variogram model (red line), and the average variogram from realisations (blue line) in three directions 


\subsection{Placement of extraction level}

The discounted profit and tonnage of the ore blocks above each ore block in each level were calculated (Equations 1 and 2), and the profit-tonnage curve was plotted for the original model (single estimated orebody model) and all realisations. The discounted profit was calculated for the block height of $10 \mathrm{~m}$ and the vertical extraction rate of $15 \mathrm{~m} /$ period. This led to the selection of the optimal horizon for starting extraction based on maximum profit for each realisation. Figure 6 shows an example of the tonnage-profit curve for one of the realisations and the histogram of the obtained extraction levels for realisations.

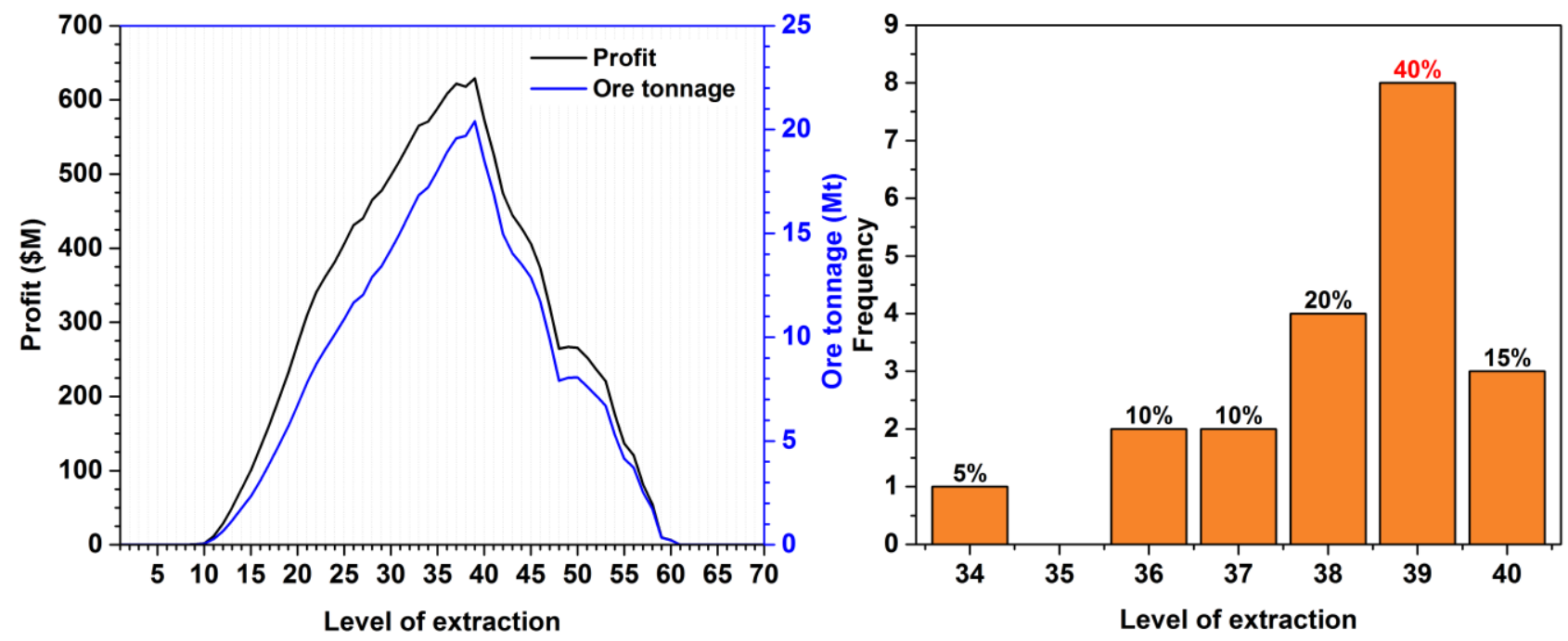

Figure 6 Selection of optimal extraction horizon based on tonnage-profit curve (left, one realisation) and histogram of the optimum level of extraction for realisations

The extraction horizon varies between levels 34 and 40 . In $40 \%$ of the realisations, level 39 is the optimum level of extraction from a NPV perspective. In addition to the realisations, a single block model was also considered. In this block model (original model), the grade estimation was done using the kriging technique. It should be noted that the optimum level of extraction for the original model was level 38 , which was identified in $20 \%$ of the realisations.

After determining the optimal extraction horizon, an optimal advancement direction was selected using the method presented by Khodayari and Pourrahimian (2015a). Then, because of the distances between drawpoints and the assumed footprint size $(30 \times 30 \mathrm{~m})$, the blocks were placed into bigger blocks along the advancement direction. Additionally, as the big-blocks close to the boundaries did not constitute a complete set (with nine small-blocks), only sets with seven or more blocks were considered. Figure 7 shows the steps involved from finding the extraction level to creating the big-blocks. 

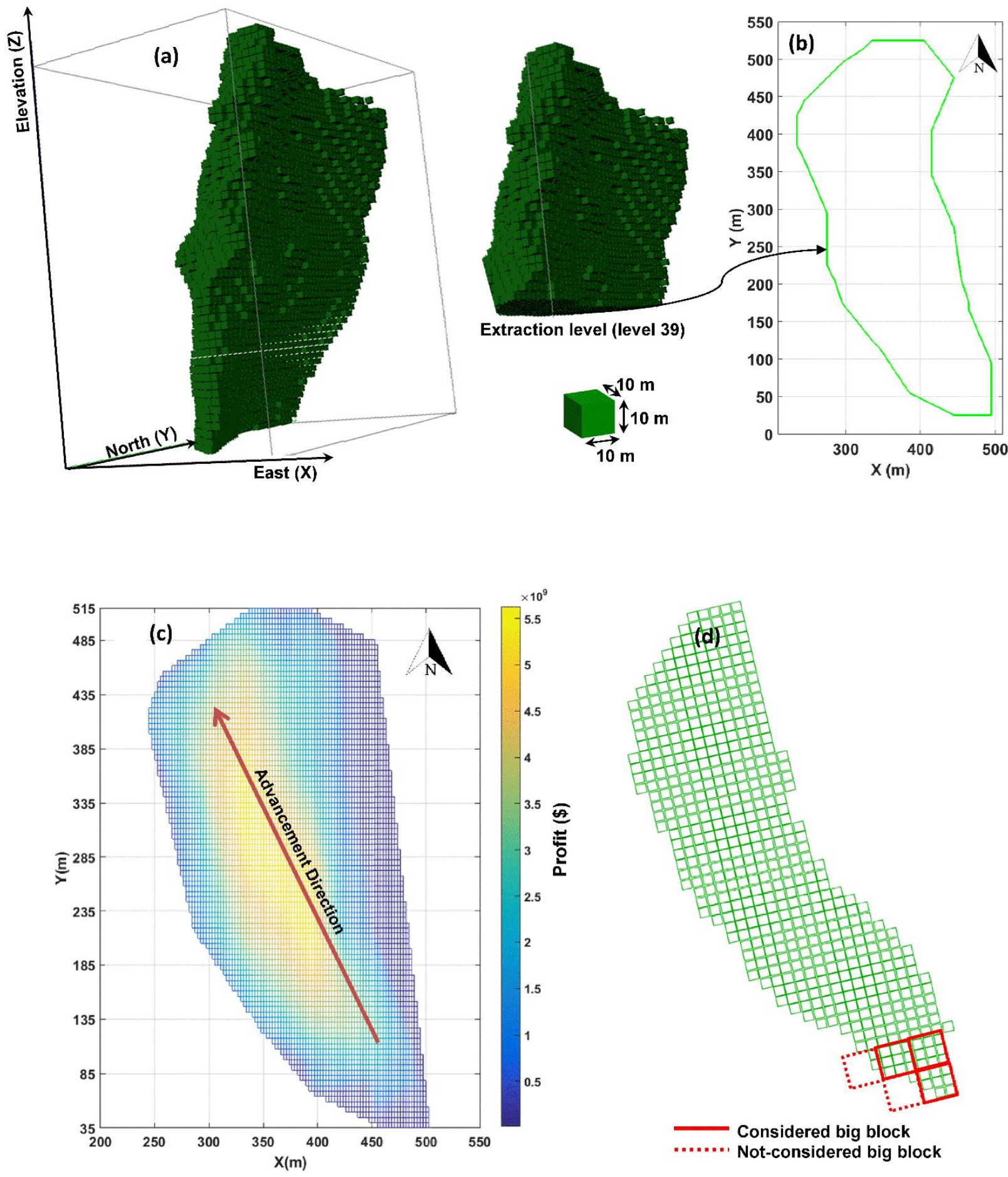

Figure 7 (a) Block model of the orebody, (b) Outline of the orebody at level 39, (c) Optimum advancement direction based on the profit at the considered level (Khodayari \& Pourrahimian 2015a); and, (d) Schematic view of considering big-blocks with more than seven small-blocks

\subsection{Production scheduling}

In order to evaluate the risks due to the presence of grade uncertainty, the changes in NPV and tonnage should be investigated. Considering the deterministic values for the grade, the original block model results in one NPV or tonnage at the end. Optimisation of the production schedule based on kriging will not assess uncertainty and will thus be suboptimal. To maximise the calculated NPV, the proposed mathematical model was applied to generate the production schedule for the original block model and realisations. Table 2 shows the scheduling parameters for the MILP model. 
Table 2 Scheduling parameters for MILP model (original and realisations)

\begin{tabular}{llll}
\hline Parameter & Value & Parameter & Value \\
\hline T (period) & 15 & $\mathrm{i}(\%)$ & 10 \\
\hline MCL (tonne) & $1,200,000$ & Recovery (\%) & 85 \\
\hline MCU (tonne) & $3,000,000$ & $\bar{N}_{N B B L, 1}$ & 28 \\
\hline GL (\%) & 1.3 & $\underline{N}_{N B B L, 1}$ & 0 \\
GU (\%) & 1.6 & $\bar{N}_{N B B L, t}$ & 5 \\
\hline ExtL (tonne) & 90,000 & $\underline{N}_{N B B L, t}$ & 2 \\
\hline ExtU (tonne) & 350,000 & $\mathrm{~L}$ & $100,000,000$ \\
\hline
\end{tabular}

Results of the original model are presented here to show that all the constraints have been satisfied. The original model had 90 big-block columns. Figure 8 shows the production grade and tonnage in each period for the optimum level of extraction in the original model. The amount of extracted ore was $37.5 \mathrm{Mt}$ with an NPV of USD 1,010 M. Figure 9 shows that the maximum mining capacity is reached from period one to period 10, then production decreases gradually until the end of the life-of-mine. It should be noted that in the solved example, ramp-up period has not been defined in the scheduling parameters. The grade of production increases gradually during the first nine periods, and the material with higher grades is extracted at first and then it decreases slowly.

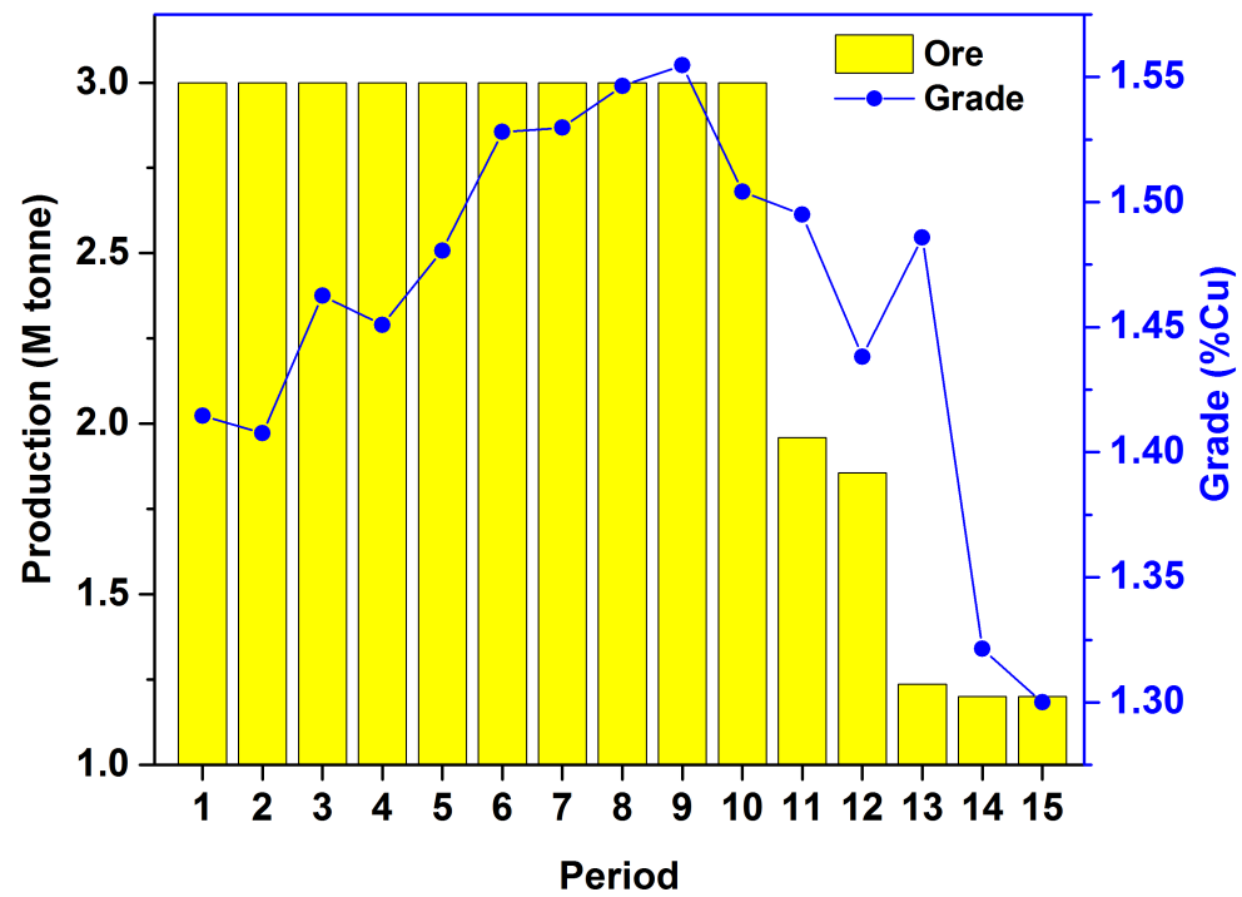

Figure 8 Ore production tonnage and average grade over the life-of-mine (original model) 


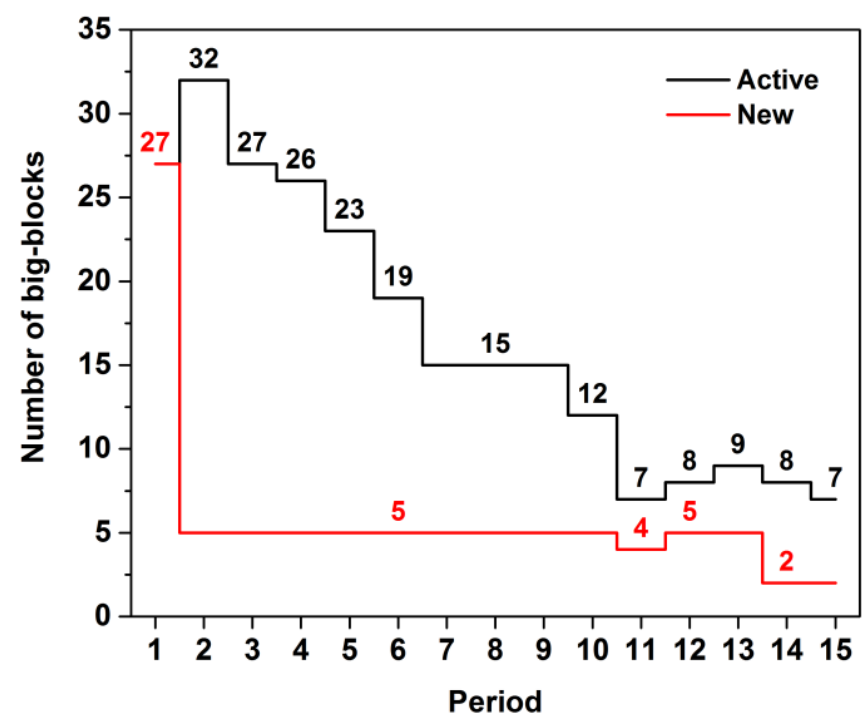

Figure 9 Number of active and new big-blocks for each period over the life-of-mine (original model)

Figure 9 shows the number of active and new big-blocks that should be opened in each period. The formulation tries to open more big-blocks at period one in order to maximise the NPV, and because of that, 27 big-blocks were opened at period one.

Figure 10 shows the frequency of NPV and production tonnage for all the realisations at their own optimum extraction horizon. As can be seen, the NPV varies between USD $965 \mathrm{M}$ and USD 1,086 M, and the mean was USD 1,026 M. The minimum and maximum ore tonnages that can be extracted were 33.2 and $39.6 \mathrm{Mt}$, respectively. The original block model's tonnage and NPV values were within the lower and upper quartile.

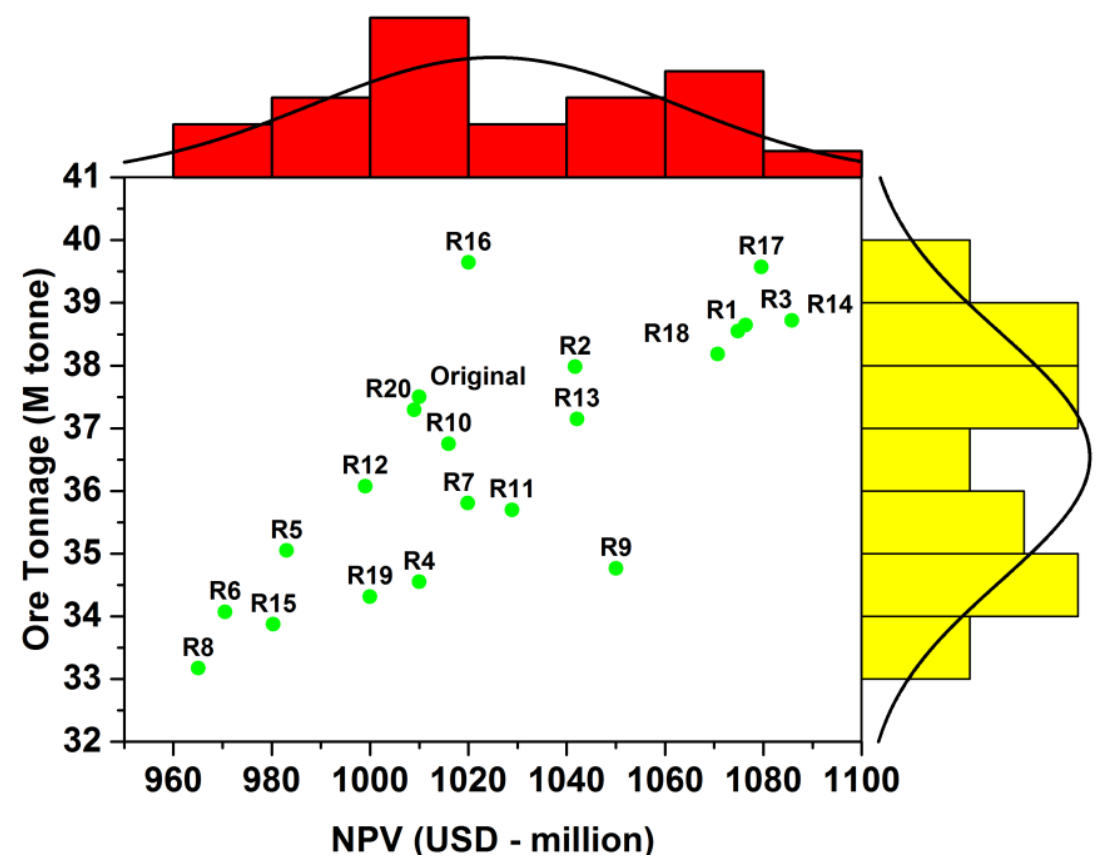

Figure 10 Histogram of NPV and extracted ore tonnage for realisations and the original model

\section{Conclusion}

Grade uncertainty has been used in open pit mining but is less studied in underground mining, especially in block caving. Typically, once a block cave is initiated, it is difficult to modify the NPV and IRR as geometric alterations to the production horizon are difficult to implement. 
This paper considers grade uncertainty and presents a methodology to identify the first-pass optimal extraction horizon for block cave mining. Ignoring the grade uncertainty during production scheduling can result in an optimistic schedule. The majority of block caving mines use kriging as the main technique to estimate resources. Therefore, the block model generated in kriging is used to identify the optimum horizon of extraction. There are a number of drawbacks, including (i) only a single response can be calculated (i.e. a single NPV), (ii) it is difficult to assess uncertainty in the response (i.e. NPV, tonnes per year, dilution, production rate, etc.), and (iii) the impact of the smoothing effect of kriging is difficult to quantify.

\section{References}

Albor Consuegra, FR \& Dimitrakopoulos, R 2009, 'Stochastic mine design optimisation based on simulated annealing: pit limits, production schedules, multiple orebody scebarios and sensitivity analysis', Transactions of the Institution of Mining and Metallurgy, vol. 118, no. 2, pp. 80-91.

Asad, MWA \& Dimitrakopoulos, R 2013, 'Implementing a parametric maximum flow algorithm for optimal open pit mine design under uncertain supply and demand', Journal of the Operational Research Society, vol. 64, no. 2, pp. 185-197.

Carpentier, S, Gamache, M \& Dimitrakopoulos, R 2016, 'Underground long-term mine production scheduling with integrated geological risk management', Mining Technology: Transactions of the Institutions of Mining and Metallurgy: Section A, vol. 125, no. 2, pp. 93-102.

Chanda, ECK 1990, 'An application of integer programming and simulation to production planning for a stratiform ore body', Mining Science and Technology, vol. 11, no. 2, pp. 165-172.

Deutsch, CV \& Journel, AG 1998, GSLIB: Geostatistical Software Library and User's Guide, Oxford University Press, New York.

Diering, $T$ 'Computational considerations for production scheduling of block cave mines', in A Karzulovic \& MA Alfaro (eds), Proceedings of the 4th International Conference and Exhibition on Mass Mining (MassMin 2004), Instituto de Ingenieros de Chile, Santiago, pp. 135-140.

Diering, T 2012, 'Quadratic programming applications to block cave scheduling and cave management', Proceedings of the 6th International Conference and Exhibition on Mass Mining (MassMin 2012), Canadian Institute of Mining, Metallurgy and Petroleum, Westmount, pp. 1-8.

Diering, T, Richter, O \& Villa, D 2008, 'Block cave production scheduling using PCBC', in H Schunnesson \& E Nordlund (eds), Proceedings of the 5th International Conference and Exhibition on Mass Mining (MassMin 2008), Luleå University of Technology, Luleå.

Dimitrakopoulos, R \& Ramazan, S 2008, 'Stochastic integer programming for optimising long term production schedules of open pit mines: methods, application and value of stochastic solutions', Mining Technology: Transactions of the Institutions of Mining and Metallurgy: Section A, vol. 117, no. 4, pp. 155-160.

Dowd, PA 1994, 'Risk assessment in reserve estimation and open-pit planning', Transactions of the Institution of Mining and Metallurgy, vol. 103, pp. A148-A154.

Epstein, R, Goic, M, Weintraub, A, Catalán, J, Santibáñez, P, Urrutia, R, Cancino, R, Gaete, S, Aguayo, A \& Caro, F 2012, 'Optimising long-term production plans in underground and open-pit copper mines', Operations Research, vol. 60, no. 1, pp. 4-17.

Grieco, N \& Dimitrakopoulos, R 2007, 'Managing grade risk stope design optimisation: Probabilistic mathematical programming model and application in sublevel stoping', Mining Technology: Transactions of the Institutions of Mining and Metallurgy: Section A, vol. 116, no. 2, pp. 49-57.

Guest, AR, Van Hout, GJ \& Von Johannides, A 2000, 'An application of linear programming for block cave draw control', Proceedings of MassMin 2000, The Australasian Institute of Mining and Metallurgy, Melbourne, pp. 461-468.

IBM 2015, IBM ILOG CPLEX, version 12.6.2, viewed 22 June 2017, http://www-01.ibm.com/support/docview.wss?uid=swg21959971

Khodayari, F \& Pourrahimian, Y 2014, 'Determination of the best height of draw in block cave sequence optimisation', Proceedings of the 3rd International Symposium on Block and Sublevel Caving (Caving 2014), pp. 457-465.

Khodayari, F \& Pourrahimian, Y 2015a, 'Determination of development precedence for drawpoints in block-cave mining', Proceedings of the 5th Aachen International Mining Symposia: Mineral Resources and Mine Development (AIMS 2015), pp. 383-391.

Khodayari, F \& Pourrahimian, Y 2015b, 'Mathematical programming applications in block-caving scheduling: A review of models and algorithms', International Journal of Mining and Mineral Engineering, vol. 6, pp. 234-257.

Khodayari, F \& Pourrahimian, Y 2016, 'Quadratic programming application in block-cave mining', Proceedings of the 1st International Conference of Underground Mining (U-Mining 2016), Universidad de Chile, Santiago, pp. 427-438.

Koushavand, B \& Askari-Nasab, H 2009, 'Transfer of geological uncertainty into mine planning', in RK Singhal, A Mehrotra, K Fytas \& $\mathrm{H}$ Ge (eds), Proceedings of the 18th International Symposium on Mine Planning and Equipment Selection (MPES 2009), Reading Matrix Inc., Calgary, pp. 462-476.

Lamghari, A \& Dimitrakopoulos, R 2012, 'A diversified Tabu search approach for open-pit mine production scheduling problem with metal uncertainty', European Journal of Operational Research, vol. 222, no. 3, pp. 642-652.

Lamghari, A, Dimitrakopoulos, R \& Ferland, J 2013, 'A variable neighbourhood decent algorithm for the open-pit mine production scheduling problem with metal uncertainty', Journal of the Operational Research Society, vol. 65, no. 9, pp. 1305-1314. 
Leite, A \& Dimitrakopoulos, R 2007, 'Stochastic optimisation model for open-pit mine planning: application and risk analysis at a copper deposit', Mining Technology: Transactions of the Institutions of Mining and Metallurgy: Section A, vol. 116, no. 3, pp. 109-118.

Lerchs, H \& Grossmann, I 1965, 'Optimum design of open-pit mines', Canadian Mining Metallurgical Bulletin, vol. 58, pp. 17-24.

Maleki, M \& Emery, X 2015, 'Joint simulation of grade and rock type in a stratabound copper deposit', Mathematical Geosciences, vol. 47, no. 4, pp. 471-495.

Montiel, L, Dimitrakopoulos, R \& Kawahata, K 2015, 'Globally optimising open-pit and underground mining operations under geological uncertainty', Mining Technology: Transactions of the Institutions of Mining and Metallurgy: Section A, vol. 125, no. 1, pp. 2-14.

Osanloo, M, Gholamnejad, J \& Karimi, B 2008, 'Long-term open pit mine production planning: a review of models and algorithms', International Journal of Mining, Reclamation and Environment, vol. 22, no. 1, pp. 3-35.

Parkinson, A 2012, Essays on Sequence Optimisation in Block Cave Mining and Inventory Policies with Two Delivery Sizes, PhD thesis, The University Of British Columbia, Vancouver.

Pourrahimian, Y 2013, Mathematical Programming for Sequence Optimisation in Block Cave Mining, PhD thesis, University of Alberta, Edmonton.

Pourrahimian, Y \& Askari-Nasab, H 2014, 'An application of mathematical programming to determine the best height of draw in block-cave sequence optimisation', Mining Technology: Transactions of the Institution of Mining and Metallurgy Section A, vol. 123, no. 3, pp. 162-172.

Pourrahimian, Y, Askari-Nasab, H \& Tannant, D 2013, 'A multi-step approach for block-cave production scheduling optimisation', International Journal of Mining Science and Technology, vol. 23, no. 5, pp. 739-750.

Rahal, D, Dudley, J \& Hout, Gv 2008, 'Developing an optimised production forecast at Northparkes E48 mine using MILP', in H Schunnesson \& E Nordlund (eds), Proceedings of the 5th International Conference and Exhibition on Mass Mining (MassMin 2008), Luleå University of Technology, Luleå, pp. 227-236.

Ramazan, S \& Dimitrakopoulos, R 2004, 'Traditional and new MIP models for production scheduling with in-situ grade variability', International Journal of Surface Mining, Reclamation and Environment, vol. 18, no. 2, pp. 85-98.

Ramazan, S \& Dimitrakopoulos, R 2013, 'Production scheduling with uncertain supply: A new solution to the open-pit mining problem', Optimisation and Engineering, vol. 14, no. 2, pp. 361-380.

Ravenscroft, P 1992, 'Risk analysis for mine scheduling by conditional simulation', Mining Technology: Transactions of the Institution of Mining and Metallurgy: Section A, vol. 101, pp. A104-A108.

Rubio, E 2002, Long Term Planning of Block Caving Operations Using Mathematical Programming Tools, Master's thesis, The University of British Columbia, Vancouver.

Rubio, E \& Diering, T 2004, 'Block cave production planning using operation research tool', in A Karzulovic \& MA Alfaro (eds), Proceedings of the 4th International Conference and Exhibition on Mass Mining (MassMin 2004), Instituto de Ingenieros de Chile, Santiago, pp. 141-149.

Sabour, SA \& Dimitrakopoulos, R 2011, 'Incorporating geological and market uncertainties and operational flexibility into open pit mine design', Journal of Mining Science, vol. 47, no. 2, pp. 191-201.

Smoljanovic, M, Rubio, E \& Morales, N 2011, 'Panel caving scheduling under precedence constraints considering mining system', Proceedings of the 35th International Symposium of Application of Computers and Operations Research in the Minerals Industry, The Australasian Institute of Mining and Metallurgy, Melbourne. pp. 407-417.

Song, X 1989, 'Caving process simulation and optimal mining sequence at Tong Kuang Yu mine, China', in A Weiss (ed.), Proceedings of the 21st Application of Computers and Operations Research in the Mineral Industry, Society of mining Engineering of the American Institute of Mining, Metallurgical, and Petroleum Engineers, Littleton, pp. 386-392.

The MathWorks, Inc. 2017, MATLAB, viewed 22 June 2017, https://au.mathworks.com/product/ltc/matlab.html

Vargas, E, Morales, N \& Emery, X 2014, 'Footprint and economic envelope calculation for block/panel caving mines under geological uncertainty', Proceedings of the 3rd International Symposium on Block and Sublevel Caving (Caving 2014), pp. 449-456.

Weintraub, A, Pereira, M \& Schultz, X 2008, 'A priori and A posteriori aggregation procedures to reduce model size in MIP mine planning models', Electronic Notes in Discrete Mathematics, vol. 30, pp. 297-302. 
